\title{
Non-Neutral Marginal Innovation Costs, Omitted Variables, and Induced Innovation
}

\author{
Daegoon Lee, Benjamin W. Cowan, and \\ C. Richard Shumway
}

\begin{abstract}
Prior tests of Hicks' Induced Innovation Hypothesis $(\mathrm{IIH})$ have been greatly hampered because the lack of supply-side data implicitly requires the untenable assumption that the marginal research cost is the same for different inputs. We document that, with appropriate model specification and panel data, a two-way fixed-effects estimator can account for much of the non-neutrality of the innovation function. Using a test procedure that is robust to a time-variant and non-neutral innovation function, we test the IIH in U.S. agriculture for the period 1960-2004. We use only readily available data for innovation demand and total public research expenditures.
\end{abstract}

Keywords: demand, two-way fixed effects, factor augmentation, induced innovation, innovation function, omitted variables, supply, U.S. agriculture

JEL Classification: 0300, D240

\section{Introduction}

The induced innovation hypothesis (IIH) postulated by Hicks (1932) more than 80 years ago has captured much attention because of the theoretical appeal that prices may be important not only for input choices but also for technology development to save inputs that become relatively more expensive. Although it took more than 30 years before the theoretical foundations began to be established (e.g., Kennedy 1964; Samuelson 1965; Ahmad 1966; Kamien and Schwartz 1968; Binswanger 1974a), Hayami and Ruttan's (1970) tests of the IIH quickly inaugurated a large body of literature devoted to determining the empirical validity of the IIH in a wide range of industries and countries.

Part of that attention is due to its important policy implications. Whether the IIH is valid in a sector or a country is important to policy makers because of the dynamic effects of economic policies. Taxes and subsidies are sometimes used

\footnotetext{
Daegoon Lee is a program evaluations manager in the Policy, Data, Performance, and Integrity Division of the Washington State Employment Security Department. Benjamin W. Cowan is an associate professor in the School of Economic Sciences, Washington State University C. Richard Shumway is a regents professor emeritus in the School of Economic Sciences, Washington State University. This research was supported by the Washington Agricultural Research Center and by the USDA National Institute of Food and Agriculture, Hatch grant WPN000275. Email: leedaegoon@gmail.com
}

Agricultural and Resource Economics Review 49/3 (December 2020) 465-491

(C) The Author(s) 2020. This is an Open Access article, distributed under the terms of the Creative Commons Attribution licence (http://creativecommons.org/licenses/by/4.0/), which permits unrestricted re-use, distribution, and reproduction in any medium, provided the original work is 
to correct market failures when prices fail to reflect externalities. If the IIH is valid, price interventions are expected to have multistage effects through research and development (R\&D) resource allocation decisions.

Despite the large body of literature that reports empirical tests of the IIH, most of it has implicitly maintained the untenable hypothesis of a neutral innovation function (i.e., that the marginal cost of $R \& D$ to augment one percent of an input is the same across inputs). Addressing non-neutral innovation is a supply-side issue, and statistical tests of the IIH have generally focused exclusively on the demand for innovation and ignored its supply dimensions.

The one exception for the agricultural sector is Cowan, Lee, and Shumway (2015). They tested the IIH using both demand-side data (input prices) from the innovation-implementing industry (U.S. production agriculture) and supplyside data (R\&D investments to save individual inputs) from one innovationcreating industry (U.S. public agricultural R\&D). They found greater evidence of support for the IIH than other recent studies that tested the hypothesis for the same industry using only demand-side data on input prices and allocations (e.g., Olmstead and Rhode 1993, Machado 1995, Liu and Shumway 2006, Liu and Shumway 2009). The challenge for following their approach in further tests is that suitable supply-side data is seldom available. For example, Cowan, Lee, and Shumway (2015) were only able to obtain data on R\&D investments that save land, labor, fertilizer, and pesticides. This is far from an exhaustive set of inputs. In fact, they represent less than half of expenditures on agricultural production inputs in the U.S. over the period 1948-2013 (USDA ERS 2017). Efforts to obtain supply-side data in other industries have proved equally challenging (e.g., Popp 2002, Crabb and Johnson 2010, Johnstone et al. 2012).

Thus, it is likely that most future tests of the IIH will have to rely on demandside data. The problem facing such approaches is how to account for differences in the marginal cost of R\&D for different inputs (i.e., a non-neutral innovation function). This paper addresses this challenge, which has seemed insurmountable. Using only readily available demand-side data and total public R\&D expenditures, we develop both a theoretical foundation and a test procedure that accounts for much of the difference in the marginal cost of R\&D for different inputs through model specification, use of panel data, and econometric technique. We approach the issue of differences in marginal costs as an omitted variables problem and use a fixed-effects estimator that accounts for an important part of the differences in marginal costs. Although we do not accommodate all sources of non-neutrality, we find greater support for the IIH than alternative models that treat the innovation function as neutral.

We postulate a representative firm for each state that makes or influences two distinct, temporally separate decisions - an R\&D resource allocation decision that is based on expected input prices and a subsequent input choice decision based on existing technology and realized input prices. We develop a multistage decision model that parametrically distinguishes intertemporal effects of the IIH from those of contemporaneous input substitution. We explicitly introduce an innovation function that is permitted to be non- 
neutral. With panel data, we show how a time-and-state two-way fixed-effects formulation can account for some of the non-neutral marginal R\&D costs in empirical estimation and thus provide a more valid test of the IIH using data only from the demand side. ${ }^{1}$

Our procedure allows marginal cost of R\&D on technology that aims to augment use of an input to vary across observational units and over time. We impose only one simplifying assumption-that the trend in the rate of change in relative marginal R\&D cost is the same across states. This time-and-state two-way fixed-effects formulation permits the cost-minimizing input ratio effects of different marginal R\&D costs across observational units and over time to be controlled for, which could have otherwise caused omitted variables bias. While our simplifying assumption is still restrictive, this assumption is much more flexible than the assumption of a neutral innovation function maintained in most previous tests. We implement our empirical test using a state-level panel for the period 1960-2004 of readily available data-input prices and quantities and total output for the innovation-implementing agricultural production industry and total R\&D expenditures for the innovation-creating public agricultural R\&D industry. The R\&D resource allocation decision is based on rational expectations of future input prices. Alternative expectation-generating mechanisms are considered as robustness checks.

Our analytical results show that when the elasticity of substitution between two inputs is less than one plus the magnitude of the innovation concavity parameter (which itself must be greater than one to ensure a concave innovation possibility frontier), a rise in the relative expected price of an input results in its relatively lower use. However, when the elasticity of substitution is greater than this magnitude, the IIH implies relatively greater use of the input that is expected to become more expensive. We document that the relationship between expected input prices and factor augmentation is a non-monotonic function of the elasticity of substitution when the innovation function is accounted for. We also find that the relationship between marginal R\&D cost and factor-saving behavior is a non-monotonic function of the elasticity of substitution.

The empirical results indicate that the state-level U.S. agricultural data during the 1960-2004 period provide moderate overall support for the IIH and strong support with some inputs. Empirical evidence of consistency with the IIH is concentrated in input decisions involving pairs of three inputs-capital, intermediate inputs, and labor. Less support is found for input pairs involving land. The level of support for the IIH is similar to other recent tests for the

\footnotetext{
1 Deininger (1995) noted that significant time dummies in a two-way fixed-effects model could be interpreted as resulting from the supply side of technology. His paper appears to be the only previous study that used two-way fixed effects to conduct a formal test of the IIH in response to changes in input prices. We document how such a model can at least partially control for a non-neutral innovation function and articulate the extent to which it can do so.
} 
IIH in this industry when innovation supply is accounted for. It is considerably greater than that found in several studies that treat innovation supply as input neutral (e.g., Olmstead and Rhode 1993, Machado 1995, Liu and Shumway 2006, Liu and Shumway 2009).

\section{Theoretical Model}

We consider a cost-minimizing firm that makes input choice decisions in period $t$ and makes or influences $R \& D$ funding decisions in $k$ earlier periods that augment technology available in period $t$. To reduce notational clutter, we ignore time subscripts in the equations in this section and refer to the time when input choice decisions are made as period 2 and the time when R\&D funding decisions are made as period 1 . We start with input choice decisions in period 2 without imposing any restrictions on factor augmentation. We then turn to the R\&D resource allocation decision in period 1 and its factor augmentation implications. By combining both components, we show how relative price changes impact both factor augmentation and subsequent input choice decisions. In doing so, we document that the IIH's implications of augmenting and saving the more expensive input is limited to certain ranges of the firm's elasticities of substitution and the innovation function's curvature parameter.

To allow parsimonious representation of a multiple-input production function with the possibility that elasticities of substitution are not the same for all input pairs, we consider a two-level constant elasticity of substitution (CES) functional form as frequently used in IIH tests (e.g., Kawagoe, Otsuka, and Hayami 1986; Thirtle Schimmelpfennig, and Townsend 2002; Piesse, Schimmelpfennig, and Thirtle 2011; Cowan, Lee, and Shumway 2015):2

$$
Y=F\left(X_{1}, X_{2}\right)=\left[\delta X_{1}^{\frac{\rho-1}{\rho}}+(1-\delta) X_{2}^{\frac{\rho-1}{\rho}}\right]^{\frac{\rho}{\rho-1}} \text { for } \rho \in[0, \infty),
$$

where $0<\rho<\infty$ is the elasticity of substitution between input indices $X_{i}>0$, $i \in(1,2)$, and $0<\delta<1$ is the share parameter. ${ }^{3}$ The input indices are produced by pairs of inputs that also follow a CES form:

$$
X_{i}=F_{i}\left(x_{i 1}, x_{i 2} ; a_{i 1}, a_{i 2}\right)=\left[\delta_{i}\left(a_{i 1} x_{i 1}\right)^{\frac{\rho_{i}-1}{\rho_{i}}}+\left(1-\delta_{i}\right)\left(a_{i 2} x_{i 2}\right)^{\frac{\rho_{i}-1}{\rho_{i}}}\right]^{\frac{\rho_{i}}{\rho_{i}-1}},
$$

2 This functional form satisfies the Gorman polar conditions for consistent aggregation (Brown 2014) and consequently is appropriate for modeling an industry of cost-minimizing firms as if it consisted of a single representative firm.

3 For greater generality, the input indices could include augmentation parameters. We suppress them because the analytical results are unaffected. 
where $x_{i j}>0$ is the quantity of input $j \in(1,2)$ used in production of input index $i$, and $a>0$ is a factor-augmenting parameter that captures technical progress, $0<\rho_{i}<\infty$ and $0<\delta_{i}<1, i \in(1,2)$. The restrictions on parameter magnitudes and input levels ensure the production function is quasi-concave and that a competitive cost-minimizing solution exists for positive input prices.

The firm selects optimal input quantities in period 2 that minimize the cost of producing a given output level with known input prices and technology. Since the two-level CES production function maintains homotheticity, minimizing cost provides the same optimal input ratios as maximizing profit with the same input prices and technology. Taking the first-order conditions and with a little reorganization documented in Appendix I, we obtain the optimal input demand relationship:

$$
\frac{x_{i 1}^{*}}{x_{i 2}^{*}}=\left(\frac{\delta_{i}}{1-\delta_{i}}\right)^{\rho_{i}}\left(\frac{w_{i 1}}{w_{i 2}}\right)^{-\rho_{i}}\left(\frac{a_{i 1 t}}{a_{i 2 t}}\right)^{\rho_{i}-1},
$$

where $w_{i j}>0$ is the price of input $x_{i j}$, and the asterisk on $x$ denotes the costminimizing input level.

Equation (3) documents that the qualitative effect of technical change (represented by the ratio of factor augmentation parameters) on the input ratio is dependent on the magnitude of the elasticity of substitution, as shown by Acemoglu (2002, 2007), Funk (2002), and Armanville and Funk (2003). Specifically, for two inputs, say labor and capital, without relative price changes, labor-augmenting technical change (that augments labor relatively more than capital) results in a labor-saving production decision if and only if the elasticity of substitution is less than one (i.e., the two factors are gross complements). However, if the inputs are gross substitutes (i.e., elasticity of substitution is greater than one), labor-augmenting technical change results in relatively greater use of labor because it is more easily substituted for capital. When the elasticity of substitution is exactly one (as in the Cobb-Douglas production function), technical change does not lead to changes in the cost-minimizing input ratio.

We now turn to the cost-minimizing R\&D resource allocation decision made in period 1. In doing so, we show that the relationship between relative price and relative factor augmentation is a non-monotonic function of the elasticity of substitution. More importantly, we document that competitive costminimizing behavior in both periods results in saving the more expensive input in period 2 even if the inputs are gross substitutes as long as the elasticity of substitution is not too large.

We consider a simple but very general homothetic innovation function that produces an innovation possibilities frontier that is strictly concave to the origin, where innovation is defined as augmentation of at least one factor. ${ }^{4}$

\footnotetext{
4 An increase in a factor augmentation parameter shifts the entire production function upward.
} But the shift may be greater in the region where the factor associated with the augmented 
It can accommodate both non-neutral and time-varying marginal R\&D costs. For a given R\&D budget $\bar{R}$, the innovation function is given by: ${ }^{5}$

$$
R_{i}=\left(c_{i 1} \hat{a}_{i 1}\right)^{\theta_{i}}+\left(c_{i 2} \hat{a}_{i 2}\right)^{\theta_{i}}
$$

where $R_{i}$ is expenditure on $\mathrm{R} \& \mathrm{D}$ in period 1 to augment the $i$ th input index, the total $R \& D$ budget is assumed to be exogenously given and fully expended, i.e., $\bar{R} \equiv R_{1}+R_{2}, \hat{a}_{i j}$ is the expected factor-augmentation in period $2 ;{ }^{6} c_{i j}>0$ denotes marginal $R \& D$ costs (or degree of $R \& D$ difficulty considering all $R \& D$ costs and probability of success) in period 1 for technology that is expected to augment $x_{i j}$ by one percent in period 2; and $\theta_{i}>1$ is a parameter representing the rate of trade-off between the two R\&D outcomes $\hat{a}_{i 1}$ and $\hat{a}_{i 2}$; that is, the larger the parameter, the more concave is the frontier to the origin (hereafter referred to as the "concavity parameter"). The marginal R\&D cost parameters represent both explicit cost (e.g., wages for scientists) and the likelihood of success in the R\&D.

The innovation function is neutral if and only if $c_{i 1}=c_{i 2}$. Figure 1 displays (a) a neutral innovation function and (b) a non-neutral innovation function. In panel (b) of the figure, the condition $c_{i 1}>c_{i 2}$ implies that R\&D on the $x_{i 1}$ inputaugmenting technology is more difficult (more costly) than that on input $x_{i 2}$ to achieve the same level of augmentation. Increases in R\&D funds expand the innovation function radially parallel to the origin. ${ }^{7}$ The condition $\theta_{i}>1$ is sufficient to ensure that $\frac{\partial \hat{a}_{i 2}}{\partial \hat{a}_{i 1}}<0$ and $\frac{\partial^{2} \hat{a}_{i 2}}{\partial \hat{a}_{i 1}^{2}}<0$ as demonstrated in Appendix II.

This simple formulation of the innovation function results in an inverse relationship between degree of R\&D difficulty and R\&D outcome. An increase in the marginal cost of R\&D shifts the innovation frontier toward the origin. Because the innovation function is output-homothetic on the frontier, the share of $R \& D$ outputs measured by the ratio of the factor-augmenting parameters does not depend on the total R\&D budget.

Considering the opportunity to invest (or influence investment) in R\&D in period 1, perhaps many years before production inputs are selected, and assuming a two-level CES production function as in the input decision, the firm's R\&D resource allocation problem in period 1 can be written as follows:

$$
\min _{\tilde{x}_{i j}, \hat{a}_{i j}} \sum_{i} \sum_{j} E\left(w_{i j}\right) \tilde{X}_{i j} \text { s.t. } \bar{Y}=\left[\delta \tilde{X}_{1}^{\frac{\rho-1}{\rho}}+(1-\delta) \tilde{X}_{2}^{\frac{\rho-1}{\rho}}\right]^{\frac{\rho}{\rho-1}} \text { and } \bar{R} \equiv R_{1}+R_{2} \text {, }
$$

parameter is used intensively, a feature similar to "localized" progress introduced by Atkinson and Stiglitz (1969) and revisited by Acemoglu (2015).

5 This function is a modified version of the one employed by Armanville and Funk (2003, p. 1633) and is similar to the innovation cost function considered in Acemoglu (2007).

6 The factor augmentation parameter is assumed to be nonregressive (that is, $\hat{a}_{i j t} \geq \hat{a}_{i j \tau}$ for $t>\tau$ ).

7 In estimation, we impose homotheticity only as a local property by including total public research expenditure as a control variable. 


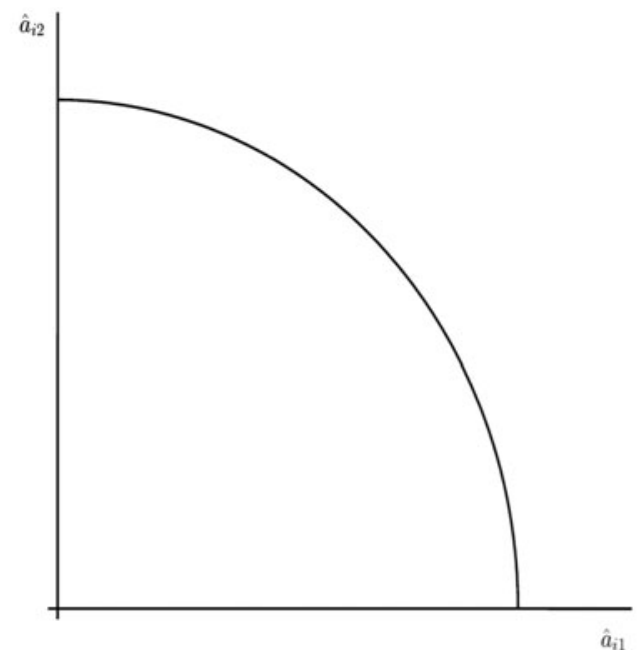

(a) Neutral Innovation Function, $c_{i 1}=c_{i 2}$

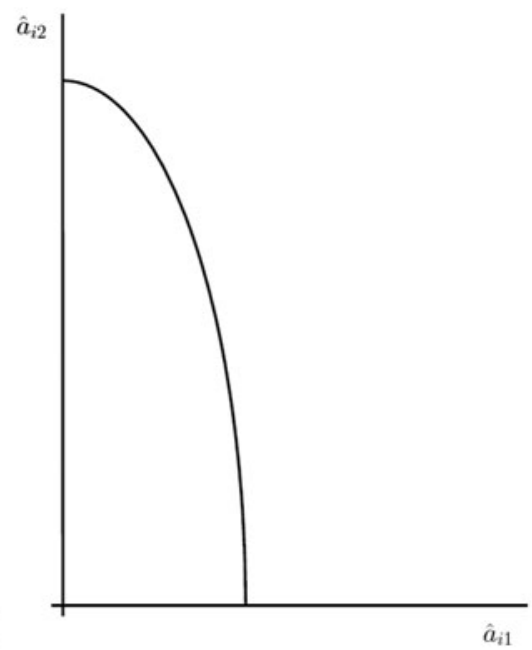

(b) Non-Neutral Innovation Function, $c_{i 1}>c_{i 2}$

\section{Figure 1. Neutral and Non-Neutral Innovation Function}

where $\tilde{X}_{i}=\left[\delta_{i}\left(a_{i 1} \tilde{x}_{i 1}\right)^{\frac{\rho_{i}-1}{\rho_{i}}}+\left(1-\delta_{i}\right)\left(a_{i 2} \tilde{x}_{i 2}\right)^{\frac{\rho_{i}-1}{\rho_{i}}}\right]^{\frac{\rho_{i}}{\rho_{i}-1}}, R_{i}=\left(c_{i 1} \hat{a}_{i 1}\right)^{\theta_{i}}+\left(c_{i 2} \hat{a}_{i 2}\right)^{\theta_{i}}$, a tilde on input level denotes that it is a period 2 value "conceived" in period 1 and thus distinguished from the value that is actually chosen by the firm in period 2 when input prices are known, $E$ is the expectations operator $E[\cdot \mid \Omega]$, and $\Omega$ is the firm's information set in period 1. Maintaining restrictions sufficient to ensure the production function is quasi-concave and the innovation possibilities frontier is strictly concave also ensures a competitive cost-minimizing solution for positive input prices.

Combining and rearranging the first-order conditions, the optimal innovation ratios in period 1 are obtained (see Appendix I for derivation of equations (6) and (7)):

$$
\frac{\hat{a}_{i 1}^{*}}{\hat{a}_{i 2}^{*}}=\left(\frac{\delta_{i}}{1-\delta_{i}}\right)^{\frac{\rho_{i}}{\psi_{i}}}\left(\frac{E\left(w_{i 1}\right)}{E\left(w_{i 2}\right)}\right)^{\frac{1-\rho_{i}}{\psi_{i}}}\left(\frac{c_{i 1}}{c_{i 2}}\right)^{\frac{-\theta_{i}}{\psi_{i}}},
$$

where $\psi_{i}=1+\theta_{i}-\rho_{i}$ and the asterisk denotes an optimal value. It is apparent that the effect of an expected price change on the ratio of expected R\&D outcomes depends on the sign and magnitude of $\frac{1-\rho_{i}}{\psi_{i}}$ and thus on the magnitudes of both $\rho_{i}$ and $\theta_{i}$ (see the first row in Table 1 ). Since $\rho_{i} \geq 0$ and $\theta_{i}>1$, an increase in the (expected) relative price of $x_{i 1}$ brings about factoraugmenting technical change such that the input that is expected to become more expensive is augmented more than the other whenever the two inputs 
Table 1. Effect of a Change in Expected Input Price Ratio, $\Delta\left(\frac{E\left(w_{i 1}\right)}{E\left(w_{i 2}\right)}\right)>0$

\begin{tabular}{lllr}
\hline Impact on & $\begin{array}{l}\text { Inputs Gross Complements } \\
\mathbf{0}<\boldsymbol{\rho}<\mathbf{1}\end{array}$ & \multicolumn{2}{l}{ Inputs Gross Substitutes } \\
\cline { 4 - 4 } $\begin{array}{l}\text { Factor augmentation } \\
\Delta\left(\frac{\hat{a}_{i 1}^{*}}{\hat{a}_{i 2}^{*}}\right)\end{array}$ & Positive & Negative & Positive \\
$\begin{array}{c}\text { Optimal input ratio } \\
\Delta\left(\frac{x_{i 1}^{*}}{x_{i 2}^{*}}\right)\end{array}$ & Negative & Negative & Positive \\
\hline
\end{tabular}

are gross complements $\left(0 \leq \rho_{i}<1\right)$. Conversely, when the inputs are gross substitutes $\left(\rho_{i}>1\right)$ and the elasticity of substitution is less than 1 plus the concavity parameter $\left(\rho_{i}<\theta_{i}+1\right)$, the same increase will induce technical change that augments the input that is expected to become less expensive. Note that the sign change at $\rho_{i}=1$ has been shown in previous literature, e.g., Acemoglu (2002). However, a new result arises in the two-period model with endogenous technical change: if the inputs are gross substitutes $\left(\rho_{i}>1\right)$ and the elasticity of substitution is greater than 1 plus the concavity parameter $\left(\rho_{i}>1+\theta_{i}\right)$, then the same increase will again induce technical change that augments the input that is expected to become more expensive. Thus, it is clear that cost-minimizing firms respond not only to price incentives but also to the technological opportunity costs in making R\&D resource allocation decisions. Further, the relationship between the elasticity of substitution and the impact of an input price change on factor augmentation is neither monotonic nor continuous. ${ }^{8}$

The firm optimizes in period 2 by solving the input choice decision problem in which the R\&D outcomes are taken as given. Substituting the expected augmentation parameters, $\hat{a}_{i 1}^{*} / \hat{a}_{i 2}^{*}$, into the equilibrium condition (3) yields the following input demand relationship:

$$
\frac{x_{i 1}^{*}}{x_{i 2}^{*}}=\left(\frac{\delta_{i}}{1-\delta_{i}}\right)^{\frac{\theta_{i} \rho_{i}}{\psi_{i}}}\left(\frac{w_{i 1}}{w_{i 2}}\right)^{-\rho_{i}}\left(\frac{E\left(w_{i 1}\right)}{E\left(w_{i 2}\right)}\right)^{\frac{-\left(1-\rho_{i}\right)^{2}}{\psi_{i}}}\left(\frac{c_{i 1}}{c_{i 2}}\right)^{\frac{\theta_{i}\left(1-\rho_{i}\right)}{\psi_{i}}},
$$

which is homogeneous of degree zero in current prices, in expected prices, and in both current and expected prices. ${ }^{9}$

\footnotetext{
8 Although not critical to the central theme of this paper, it is apparent that the qualitative impact of a change in the marginal cost of research on factor augmentation is also dependent on the magnitudes of $\rho_{i}$ and $\theta_{i}$.

9 Our assumptions of a quasi-concave production function and strictly concave innovation possibilities frontier also ensure that the cost function is homogeneous of degree 1, concave, and monotonically increasing in prices.
} 
With this combined condition, it is now easy to distinguish optimal input choice effects of technical change caused by changes in the expected price ratio from input substitution effects caused by changes in the current price ratio. As with factor augmentation, the effect of an expected relative price change on the optimal input ratio depends on the magnitudes of both $\rho_{i}$ and $\theta_{i}$ (see the second row in Table 1). An increase in the expected input price ratio, $\frac{E\left(w_{i 1}\right)}{E\left(w_{i 2}\right)}$, results in a production decision to save the input that becomes more expensive only if inputs are gross complements $\left(0 \leq \rho_{i}<1\right)$ or if they are gross substitutes $\left(\rho_{i}>1\right)$ and the elasticity of substitution is less than 1 plus the concavity parameter $\left(\rho_{i}<\theta_{i}+1\right)$. If the inputs are gross substitutes $\left(\rho_{i}>1\right)$ and the elasticity of substitution is greater than 1 plus the concavity parameter $\left(\rho_{i}>1+\theta_{i}\right)$, the increase results in a production decision to save the input that becomes less expensive. ${ }^{10}$ Our parametric relationships are qualitatively the same as Acemoglu's (2007, Example I) static results when $\rho_{i}<1$ and when $\rho_{i}>1+\theta_{i}$. When $\rho_{i}>1+\theta_{i}$, both the static and two-period results show that the demand curve for an input can be positively sloped in the long run. However, our two-period result differs from his static result when $1<\rho_{i}<1+\theta_{i}$.

\section{Empirical Model - Two-Way Fixed-Effects Approach}

In this section we document how a time-and-state two-way fixed-effects formulation can be used to control for unobserved non-neutral marginal R\&D costs. We focus on the agricultural production sector and treat states as though they were price-taking cost-minimizing firms, a hypothesis previously not rejected by empirical testing (Lim and Shumway 1992). Although little formal $R \& D$ is conducted by agricultural firms, they may have influence through the political process on the allocation of public R\&D funds. Thus, we treat public agricultural $\mathrm{R} \& \mathrm{D}$ in the state as an appendage to the representative state-level agricultural firm.

Including the state subscript $s$, time subscript $t$ on period 2 variables, and time subscript $t-k$ on period 1 variables and expectations, and taking the natural logarithm of both sides of equation (7), we obtain the regression model:

$$
\begin{aligned}
\ln \left(\frac{x_{i 1 s t}}{x_{i 2 s t}}\right)= & \beta_{i 0}+\beta_{i 1} \ln \left(\frac{w_{i 1 s t}}{w_{i 2 s t}}\right)+\beta_{i 2} \ln \left(\frac{E_{t-k}\left(w_{i 1 s t}\right)}{E_{t-k}\left(w_{i 2 s t}\right)}\right)+\beta_{i 3} \ln \left(\frac{c_{i 1 s(t-k)}}{c_{i 2 s(t-k)}}\right) \\
& +\Gamma_{i}^{\prime} Z_{i s t}+\varepsilon_{i s t}
\end{aligned}
$$

\footnotetext{
10 The qualitative impact of a change in the marginal cost of research on the input choice decision is also dependent on the magnitudes of $\rho_{i}$ and $\theta_{i}$ and is not monotonic.
} 
where $Z$ is a vector of other control variables, $\varepsilon_{\text {ist }}$ is an error term, and the $\beta^{\prime}$ s and the vector $\Gamma$ are parameters. The parameters $\beta_{i 1}, \beta_{i 2}$, and $\beta_{i 3}$ correspond to $-\rho_{i}, \frac{-\left(1-\rho_{i}\right)^{2}}{\psi_{i}}$, and $\frac{\theta_{i}\left(1-\rho_{i}\right)}{\psi_{i}}$, respectively, in equation (7). ${ }^{11}$ Empirical support for the IIH (i.e., factor-saving behavior in response to the relative price increase) is provided by a significantly negative $\beta_{i 2}$, the coefficient on the expected input price ratio. ${ }^{12}$

If the marginal cost of R\&D to augment one percent of an input is the same across inputs, i.e., $c_{i 1 t}=c_{i 2 t}$ (which represents a neutral innovation function), the ratio of marginal $R \& D$ costs vanishes from the regression model and does not affect the optimal input ratio. With few exceptions (e.g., Deininger 1995, Fulginiti 1994), this has been implicitly assumed in the IIH testing literature until recently. Formal tests have been intrinsically limited to the demand side without accounting for possible non-neutrality in the supply of innovation. However, there is no reason to expect that the innovation function is neutral, so we must deal with the omitted variables problem due to the lack of explicit data on marginal $R \& D$ costs. To surmount this problem, we use a two-way fixed-effects approach in which we allow marginal costs to vary across inputs, across states, and over time.

The time-difference equation can be written as follows:

$$
\begin{aligned}
& \Delta_{t} \ln \left(\frac{x_{i 1 s t}}{x_{i 2 s t}}\right)=\beta_{i 1} \Delta_{t} \ln \left(\frac{w_{i 1 s t}}{w_{12 s t}}\right)+\beta_{i 2} \Delta_{t} \ln \left(\frac{E_{t-k}\left(w_{i 1 s t}\right)}{E_{t-k}\left(w_{i 2 s t}\right)}\right)+\beta_{i 3} \Delta_{t} \ln \left(\frac{c_{i 1 s(t-k)}}{c_{i 2 s(t-k)}}\right) \\
& +\Gamma_{i}^{\prime} \Delta_{t} Z_{i s t}+\Delta_{t} \varepsilon_{i s t}
\end{aligned}
$$

where $\Delta_{t}$ is the time-difference operator. If the ratio of marginal $\mathrm{R} \& \mathrm{D}$ costs varies across states but is invariant over time, then

$$
\Delta_{t} \ln \left(\frac{c_{i 1 s(t-k)}}{c_{i 2 s(t-k)}}\right)=\ln \left(\frac{c_{i 1 s(t-k)}}{c_{i 2 s(t-k)}} \frac{c_{i 2 s(t-k-1)}}{c_{i 1 s(t-k-1)}}\right)=\ln \left(\frac{c_{i 1 s}}{c_{i 2 s}} \frac{c_{i 2 s}}{c_{i 1 s}}\right)=0
$$

and the equation would be estimable in its current form without data on marginal R\&D costs. However, since it is unknown whether the marginal $\mathrm{R} \& \mathrm{D}$ cost is invariant over time, we estimate the two-way fixed-effects

11 These three parameters of equation (8) overidentify the two parameters in equation (7). Since our subsequent estimation procedure does not require us to estimate $\beta_{i 3}$, this overidentification disappears.

12 For factor-saving behavior to also be consistent with cost minimizing behavior, the elasticity of substitution must be greater than zero and less than $1+\theta_{i}$. Since $\theta_{i}>1$, factor-saving behavior is clearly consistent with cost-minimizing behavior if $0<\rho_{i}<2$, i.e., $0>\beta_{i 1}>-2$. 
formulation:

$$
\begin{aligned}
& \Delta_{t, s} \ln \left(\frac{x_{i 1 s t}}{x_{12 s t}}\right)=\beta_{i 1} \Delta_{t, s} \ln \left(\frac{w_{i 1 s t}}{w_{i 2 s t}}\right)+\beta_{i 2} \Delta_{t, s} \ln \left(\frac{E_{t-k}\left(w_{i 1 s t}\right)}{E_{t-k}\left(w_{i 2 s t}\right)}\right)+\beta_{i 3} \Delta_{t, s} \ln \left(\frac{c_{i 1 s(t-k)}}{c_{i 2 s(t-k)}}\right) \\
& +\Gamma_{i}^{\prime} \Delta_{t, s} Z_{i s t}+\Delta_{t, s} \varepsilon_{i s t}
\end{aligned}
$$

where $\Delta_{t, s}$ is the time-and-state difference operator. Thus, defining the change rate term,

$$
\begin{aligned}
& g_{i 1(t-k)}=\frac{c_{i 1(t-k)}}{c_{i 1(t-k-1)}} \\
& \Delta_{t, s} \ln \left(\frac{c_{i 1 s(t-k)}}{c_{i 2 s(t-k)}}\right)=\ln \left(\frac{g_{i 1 s(t-k)}}{g_{i 2 s(t-k)}} / \frac{g_{i 1 \bar{s}(t-k)}}{g_{i 2 \bar{s}(t-k)}}\right),
\end{aligned}
$$

where $\bar{s} \neq s$ is a reference state.

We maintain the sufficient condition that the change rate in relative marginal costs of R\&D over time is equal across states. ${ }^{13}$ More restrictive assumptions such as state-invariant marginal R\&D costs (as typically assumed) and/or time-invariance are sufficient but not necessary for the equation to be identified. Importantly, identification under our sufficient condition does not require identical marginal $R \& D$ costs across inputs, and thus the equation is estimable with a non-neutral innovation function even without data on marginal R\&D costs. Further, the assumption still allows for differences in marginal R\&D costs across states and for changes in the innovation function over time so long as the pattern of change is common across states.

If the sufficient condition noted above holds, the two-way fixed-effects formulation surmounts the omitted variable problem caused by the lack of marginal R\&D cost data and makes estimation of $\beta_{i 3}$ unnecessary. To the extent that condition is not a reasonable approximation, this approach is unable to fully capture the effects of a non-neutral innovation function. Equation (10) is estimated using a two-way fixed-effects (state and time) panel data estimator. ${ }^{14}$

We include two additional control variables-total public agricultural R\&D expenditures for each state $s$ and year $t-k$ and total agricultural output for each state $s$ and year $t$. These variables are included to control for potential size effects of total R\&D expenditures in the innovation creation industry and

\footnotetext{
13 Without innovation supply data, there does not appear to be any way to account for all types of non-neutrality in the innovation function. This approach allows us to deal with three of the four types of non-neutrality-across inputs, states, and time.

14 Although our identification strategy requires a fixed-effects estimator, we also conducted the Hausman test using the rational expectations price model. The hypothesis of random effects was rejected at the 0.01 significance level in all input pairs, so the data also support fixed effects as the preferred specification.
} 
of total agricultural output in the innovation-implementation industry. Inclusion of these control variables renders homotheticity as a local property rather than a global constraint for both the production function and the innovation function.

\section{Data and Variable Specification}

The data used for our test of the IIH include annual agricultural input quantities and prices for four exhaustive input categories (land, non-land capital, labor, and intermediate inputs) as well as total agricultural output and total public expenditures for agricultural productivity $R \& D$ for each of the 48 contiguous U.S. states for the years 1960-2004. The panel data set is balanced over the entire period. Summary statistics are presented in Table 2.

The agricultural input prices and quantities and total output are from the U.S. Department of Agriculture (USDA ERS 2015). For details regarding original data sources and construction of this state-level aggregated series, see Ball, Hallahan, and Nehring (2004) and Ball et al. (1999). Total annual public expenditures for agricultural productivity R\&D by state are from Huffman (2012). They were compiled following the procedures outlined in Huffman (2015). Specifically, R\&D expenditure data collected by the USDA in its Current Research Information System (CRIS) were used. CRIS includes funding from all sources for agricultural $R \& D$ undertaken by both federal R\&D organizations (U.S. Department of Agriculture) and state public R\&D entities (state agricultural experiment stations and veterinary colleges at land grant universities). Expenditures on post-harvest $R \& D$ and $R \& D$ on households, families, and communities were excluded from Huffman's series.

\section{Expected Prices and Forecasting}

In the theory of induced innovation, it is the expectation of future input prices that drives invention to economize "the use of a factor which has become relatively expensive" (Hicks 1932). Thus, for consistency with the IIH, expected future prices should be a key determinant in $R \& D$ resource allocation decisions. The challenge is to determine how future price expectations are formulated. Much of the empirical IIH testing literature has relied on adaptive expectation formulations (e.g., Popp 2002, Esposti and Pierani 2006, Crabb and Johnson 2010, Cowan, Lee, and Shumway 2015). Although they are easy to implement, adaptive expectations suffer from the conceptual drawback that they are backward-looking. As such, they embed systematic errors from previous forecasts (Hommes 1998). To overcome this conceptual problem of adaptive expectations, we use rational expectations in our base model to forecast future input prices. ${ }^{15}$ Rational expectations theory

\footnotetext{
15 We use adaptive expectations for a robustness check. Futures prices are also frequently used as expected commodity prices in economic analysis. Although they are often regarded as rational
} 
Table 2. Summary Statistics

\begin{tabular}{|c|c|c|c|c|c|}
\hline Variable & Unit & Mean Value & Standard Deviation & Minimum Value & Maximum Value \\
\hline Land price & Index $^{a}$ & 0.606616 & 0.575 & 0.006 & 3.631 \\
\hline Labor price & Index $^{a}$ & 0.439577 & 0.334 & 0.048 & 2.110 \\
\hline Capital price & Index $^{a}$ & 0.638603 & 0.370 & 0.129 & 1.237 \\
\hline Intermediate inputs price & Index ${ }^{a}$ & 0.887015 & 0.382 & 0.224 & 2.022 \\
\hline Land quantity & Thousands of $\$ 1996^{\mathrm{b}}$ & 714,651 & 758,782 & 4,014 & $5,155,293$ \\
\hline Labor quantity & Thousands of $\$ 1996^{\mathrm{b}}$ & $1,971,694$ & $1,742,262$ & 18,189 & $9,476,398$ \\
\hline Capital quantity & Thousands of $\$ 1996^{\mathrm{b}}$ & 662,047 & 591,411 & 7,350 & $3,330,621$ \\
\hline Intermediate inputs quantity & Thousands of $\$ 1996^{\mathrm{b}}$ & $1,761,636$ & $1,636,347$ & 12,918 & $9,454,613$ \\
\hline Total agricultural output & Thousands of $\$ 1996^{b}$ & $3,814,100$ & $3,846,671$ & 42,552 & $30,129,558$ \\
\hline Total public R\&D expenditure & Thousands of \$ 1996 & 19,888 & 17,150 & 487 & 111,612 \\
\hline
\end{tabular}

${ }^{a}$ Measured relative to a 1996 Alabama price of 1.00 .

${ }^{\mathrm{b}}$ Measured as the value of the input, in thousands of dollars, used for agricultural production in the state divided by the price index. 
postulates that economic agents use all relevant information so their forecasting is not prone to systematic errors.

To obtain forecasted future input prices that are consistent with rational expectations theory, we identified the autoregressive (AR) structure for each input price to ensure that the forecasted prices based on the AR model give zero expected errors. ${ }^{16}$ This was done by first using the Im-Pesaran-Shin (2003) test for nonstationarity of the panel price data and then fitting an AR model consistent with the time series test results. ${ }^{17}$ The detailed development of our rational expectation forecasts is reported in Appendix III.

\section{$R \& D \operatorname{Lag}$}

The importance of expected price rather than current price in testing the IIH comes from the fact that there is a lag between R\&D efforts by the innovation-creating industry and use of new technology by the innovationimplementing industry. In our theoretical model, we treat both activities as embodied within the same firm. In reality, they may be entirely separate entities. The theoretical model still applies as long as the innovationimplementing firm can influence decisions by the innovation-creating unit.

We test the IIH allowing for the technology in any year to be affected most by $R \& D$ conducted five years earlier. The appropriate length of the lag is uncertain and is a subject of research itself. To examine the IIH in the U.S. energy sector, Popp (2002) employed up to 20 years of lagged prices while Crabb and Johnson (2010) used only 24 months of lagged prices. Cowan, Lee, and Shumway (2015) used ten years of lagged prices to test the hypothesis in U.S. agriculture. A strand of literature has focused on measuring the lag between research and its impact on productivity in U.S. agriculture (e.g., Chavas and Cox 1992, Huffman and Evenson 2006, Wang et al. 2013). Our choice of five years is much shorter than their findings and is motivated by the short length of our price data series. Public agricultural R\&D expenditure data are available much earlier but are only useful in the estimation if input price data are also available. The latter are required to create expectations of future prices at the time R\&D investment occurs.

To keep more observations in the statistical estimation and to retain data consistency with the rational expectations formulation (e.g., one input price requires seven years of data in the autoregressive structure), we truncated

expectations (e.g., Gardner 1976, Bray 1981, Shonkwiler and Maddala 1985), they are not available for many agricultural inputs, and their performance as price expectations has been mixed in a variety of economic models (e.g., McIntosh and Shumway 1994, Gertchev 2007).

16 While rational expectation formulations can follow structures other than AR, AR is typically used because of its simplicity and because it ensures that the expected error is zero.

17 Other than the nonstationarity tests conducted to identify the appropriate AR structure for input prices, no other time series tests were conducted due to the relatively short length of the data period and the low power of cointegration tests for short data spans (Pedroni 2004). 
the number of expected prices that are assumed to affect $R \& D$ resource allocation decisions at five years. Such a short lag structure prevents our analysis from picking up the effect of early research funding decisions. Thus, we are only able to benefit from decisions late in the R\&D funding process.

We considered two options: (a) a single price expectation given information available at $t-k$, where $k=5$, which implies that R\&D conducted five years earlier is primarily responsible for changes in current technology, and (b) a weighted average of price expectations for $k=2, \ldots, 5$, which implies that $\mathrm{R} \& \mathrm{D}$ conducted between two and five years earlier is primarily responsible for changes in current technology. For the latter, we used weights for the first five years of Wang et al.'s (2013) trapezoidal structure for private research stock. Specifically, weights of $0.1,0.2,0.3$, and 0.4 were assigned to the expectations made between two and five years earlier, respectively. Using a weighted average of price expectations amounts to solving the cost minimization problem, equation (5), with the objective function $\sum_{h=2}^{5} \sum_{i} \sum_{j} \omega_{h} E_{t-h}\left(w_{i j s t}\right) \tilde{x}_{i j s t}$ where $\omega$ denotes the weights.

\section{Test Results}

The estimation model, equation (10), was estimated using a two-way fixedeffects panel data estimator. The statistical estimates based on rational price expectations are presented in Table 3. Estimation results are reported from two model specifications in which only price expectation differed: the first used a single price expectation lagged five years and the second used a weighted average of expected prices lagged two to five years. Each column contains estimates for one input pair.

For comprehensive coverage, we tested for consistency with the IIH by considering all six exhaustive pairs of the four inputs (i.e., labor/land, capital/land, intermediate inputs/land, capital/labor, intermediate inputs/ labor, and intermediate inputs/capital). Due to potential heteroskedasticity and autocorrelation, robust standard errors were obtained using a clustered sandwich estimator with the state as the unit of cluster (Wooldridge 2002). ${ }^{18}$ Time and state fixed effects were included in all equations, but these estimates are not reported in the table to conserve space. The number of observations included in each of the regressions varied across input ratios due to the different number of lags involved in the calculation of rational expectations of future price.

\footnotetext{
18 Based on the Wooldridge test, the hypothesis of no serial correlation was rejected in each input pair at the 0.01 significance level. Clustering in the computation of robust standard errors takes care of serial correlation. In the applied microeconomics literature, using robust standard errors from an unbiased estimator is generally regarded as the preferred way to deal with potential serial correlation. FGLS is an alternative, but its potential for increased efficiency comes only with the imposition of additional assumptions that may result in misspecification (Bertrand, Duflo, and Mullainathan 2004).
} 
Table 3. Statistical Estimates with Rational Expectation Price Forecasts ${ }^{\text {a }}$

\begin{tabular}{|c|c|c|c|c|c|c|}
\hline Parameter & Labor/Land & Capital/Land & $\begin{array}{l}\text { Intermediate } \\
\text { inputs/Land }\end{array}$ & Capital/Labor & $\begin{array}{l}\text { Intermediate } \\
\text { inputs/Labor }\end{array}$ & $\begin{array}{l}\text { Intermediate } \\
\text { inputs/Capital }\end{array}$ \\
\hline \multicolumn{7}{|c|}{ A single price expectation lagged five years } \\
\hline $\begin{array}{l}\text { Current price ratio } \\
\quad\left(\beta_{i 1}\right)\end{array}$ & $\begin{array}{c}-0.19787^{* * *} \\
(0.03419)\end{array}$ & $\begin{array}{c}-0.04478 \\
(0.03628)\end{array}$ & $\begin{array}{c}-0.08009^{* *} \\
(0.04247)\end{array}$ & $\begin{array}{c}-0.29171^{* * *} \\
(0.03431)\end{array}$ & $\begin{array}{c}-0.35002^{* * *} \\
(0.03573)\end{array}$ & $\begin{array}{c}-0.54031^{* * *} \\
(0.08229)\end{array}$ \\
\hline $\begin{array}{l}\text { Expected future } \\
\text { price ratio }\left(\beta_{i 2}\right)\end{array}$ & $\begin{array}{c}-0.11118^{* *} \\
(0.06607)\end{array}$ & $\begin{array}{c}-0.13664^{* * *} \\
(0.06682)\end{array}$ & $\begin{array}{r}-0.09704^{*} \\
(0.06507)\end{array}$ & $\begin{array}{c}-0.15303^{*} \\
(0.11034)\end{array}$ & $\begin{array}{c}-0.16168 \\
(0.13213)\end{array}$ & $\begin{array}{c}-0.20492^{* * *} \\
(0.08504)\end{array}$ \\
\hline $\begin{array}{l}\text { Total agricultural } \\
\text { output }\end{array}$ & $\begin{array}{l}0.36315^{* * *} \\
(0.10030)\end{array}$ & $\begin{array}{l}0.19109^{* * *} \\
(0.05091)\end{array}$ & $\begin{array}{l}0.82940^{* * *} \\
(0.08701)\end{array}$ & $\begin{array}{c}-0.11165 \\
(0.09053)\end{array}$ & $\begin{array}{l}0.50564^{* * *} \\
(0.11606)\end{array}$ & $\begin{array}{l}0.62433^{* * *} \\
(0.06987)\end{array}$ \\
\hline $\begin{array}{l}\text { Total public R\&D } \\
\text { funds }\end{array}$ & $\begin{array}{c}0.01343 \\
(0.06747)\end{array}$ & $\begin{array}{c}0.06810 \\
(0.04315)\end{array}$ & $\begin{array}{c}-0.00440 \\
(0.04068)\end{array}$ & $\begin{array}{l}0.09368^{* *} \\
(0.04078)\end{array}$ & $\begin{array}{c}0.01005 \\
(0.04598)\end{array}$ & $\begin{array}{c}-0.08779^{* * *} \\
(0.02859)\end{array}$ \\
\hline Constant & $\begin{array}{c}-4.49910^{* * *} \\
(1.44822)\end{array}$ & $\begin{array}{c}-2.76671^{* * *} \\
(0.77475)\end{array}$ & $\begin{array}{c}-11.06790^{* * *} \\
(1.32141)\end{array}$ & $\begin{array}{c}0.67070 \\
(1.29626)\end{array}$ & $\begin{array}{c}-7.07749^{* * *} \\
(1.72343)\end{array}$ & $\begin{array}{c}-7.65521^{* * *} \\
(1.02867)\end{array}$ \\
\hline \multirow{2}{*}{$\begin{array}{l}\text { R\&D concavity } \\
\quad \text { parameter }\left(\theta_{i}\right)^{\mathrm{b}}\end{array}$} & 4.98499 & 5.72251 & 7.80056 & 2.56998 & 1.96304 & 0.57151 \\
\hline & $(3.65915)$ & $(3.49600)$ & $(5.76520)$ & $(2.44010)$ & $(2.19680)$ & $(0.73951)$ \\
\hline R-square & 0.43977 & 0.67243 & 0.66757 & 0.43559 & 0.75363 & 0.89067 \\
\hline $\begin{array}{l}\text { Number of } \\
\text { Observations }\end{array}$ & 1,584 & 1,584 & 1,584 & 1,776 & 1,824 & 1,776 \\
\hline \multicolumn{7}{|c|}{ A weighted average of price expectations lagged two-five years } \\
\hline $\begin{array}{l}\text { Current price ratio } \\
\quad\left(\beta_{i 1}\right)\end{array}$ & $\begin{array}{c}-0.19950^{* * *} \\
(0.03198)\end{array}$ & $\begin{array}{c}-0.03171 \\
(0.03322)\end{array}$ & $\begin{array}{r}-0.07112^{*} \\
(0.04374)\end{array}$ & $\begin{array}{c}-0.28332^{* * *} \\
(0.03289)\end{array}$ & $\begin{array}{c}-0.33322^{* * *} \\
(0.03428)\end{array}$ & $\begin{array}{c}-0.53087^{* * *} \\
(0.07833)\end{array}$ \\
\hline $\begin{array}{l}\text { Expected future } \\
\text { price ratio }\left(\beta_{i 2}\right)\end{array}$ & $\begin{array}{c}-0.01243 \\
(0.03947)\end{array}$ & $\begin{array}{c}-0.05083 \\
(0.04029)\end{array}$ & $\begin{array}{c}-0.03864 \\
(0.03809)\end{array}$ & $\begin{array}{c}-0.08158^{* *} \\
(0.04748)\end{array}$ & $\begin{array}{c}-0.11449^{* *} \\
(0.05232)\end{array}$ & $\begin{array}{c}-0.18466^{* * *} \\
(0.07443)\end{array}$ \\
\hline $\begin{array}{l}\text { Total agricultural } \\
\text { output }\end{array}$ & $\begin{array}{l}0.35015^{* * *} \\
(0.10120)\end{array}$ & $\begin{array}{l}0.18702^{* * *} \\
(0.05132)\end{array}$ & $\begin{array}{l}0.82752^{* * *} \\
(0.08737)\end{array}$ & $\begin{array}{c}-0.10617 \\
(0.08916)\end{array}$ & $\begin{array}{l}0.51089^{* * *} \\
(0.11374)\end{array}$ & $\begin{array}{l}0.62681^{* * *} \\
(0.07005)\end{array}$ \\
\hline
\end{tabular}




$\begin{array}{lcccccc}\text { Total public R\&D } & 0.01332 & 0.06898 & -0.00392 & 0.09772^{* *} & 0.01473 & -0.08867^{* * *} \\ \quad \text { funds } & (0.06634) & (0.04291) & (0.04091) & (0.04082) & (0.04608) & (0.02872) \\ \text { Constant } & -4.22069^{* * *} & -2.64218^{* * *} & -11.07869^{* * *} & 0.54001 & -7.17650^{* * *} & -7.69130^{* * *} \\ & (1.45744) & (0.75843) & (1.31140) & (1.27949) & (1.68790) & (1.03056) \\ \text { R\&D concavity } & 50.75222 & 17.47722 & 21.40078 & 5.57935 & 3.21649 & 0.722698 \\ \quad \text { parameter }\left(\theta_{i}\right)^{\mathrm{b}} & (164.35842) & (14.81224) & (21.62498) & (3.76596) & (1.88834) & (0.83070) \\ \text { R-square } & 0.43655 & 0.66879 & 0.66621 & 0.43467 & 0.75404 & 0.89084 \\ \text { Number of } & 1,584 & 1,584 & 1,584 & 1,776 & 1,824 & 1,776 \\ \quad \text { Observations } & & & & & & \end{array}$

${ }^{\text {a }}$ Standard errors are in parentheses; p-value of estimated parameters: ${ }^{*} p<0.1{ }^{* *} p<0.05,{ }^{* * *} p<0.01$. The t-tests conducted for the coefficients on current and expected price ratios are one-tailed tests (with the null hypothesis that the coefficient is greater than or equal to zero). T-tests for coefficients on other regressors are two-tailed tests (null hypothesis that the coefficient is equal to zero). Time fixed effects and state fixed effects parameter estimates are suppressed.

${ }^{\mathrm{b}}$ Standard errors of the R\&D concavity parameter are obtained using the delta method. 
Estimates of the effect of the current price ratio on the input quantity ratio, $\beta_{i 1}$, are the negative of the estimated elasticity of substitution, $\rho_{i}$, and estimates of the effect of the expected future price ratio on the input quantity ratio correspond to $\beta_{i 2}$ in equation (10). For all 12 estimated equations in this table, the elasticity of substitution was estimated to be substantially less than $2.0(0.03-0.54){ }^{19}$ Thus, empirical support for the IIH and costminimizing behavior is provided by a significantly negative $\beta_{i 2}$.

Using a single price expectation based on the information set available five years earlier, five of the six pairings of inputs (83\%) supported the IIH: labor/land, capital/land, intermediate inputs/land, capital/labor, and intermediate inputs/capital. Using a weighted average of price expectations given the information set available two to five years earlier, three equations (50\%) supported the IIH: capital/labor, intermediate inputs/labor, and intermediate inputs/capital. Apart from statistical significance, the estimated signs on the expected future price ratio as well as on the current price ratio are negative for all 12 equations, and thus the directional impact of technical change inferred from the point estimates are found to be consistent with the IIH in all the estimated equations.

Effects of total agricultural output were estimated to have a significantly positive effect in 10 of the 12 equations and an insignificantly negative effect in the other two. Based on the results, we conclude that increases in total output lead to more intense use of non-land inputs (i.e., labor, capital, and intermediate inputs) than land-see the first three columns of Table 3-and to more intense use of intermediate inputs (energy, fertilizer, etc.) than labor and capital-see the last two columns. These results that reject the null hypothesis imply that the agricultural production function is not globally homothetic.

Total public R\&D funds were estimated to have a significantly positive effect in two equations and a significantly negative effect in two, while the rest were statistically insignificant. These results cause us to reject the hypothesis that the innovation function is globally homothetic. They imply that increases in total R\&D funds lead to behavior that saves labor and intermediate inputs relative to capital. Consequently, the evidence implies that the marginal cost of R\&D to save 1 percent of the capital input relative to that of labor or intermediate inputs increases as total R\&D investment increases. Non-homotheticity of the innovation function could have biased several earlier studies away from consistency with the IIH as it renders neutrality only as a local property. For example, in both Binswanger (1974b) and Huffman and Evenson (1989), a locally non-neutral innovation function could have contributed to their rejection of changes in machinery use being consistent with the induced

\footnotetext{
19 Because each estimated elasticity of substitution is less than one, they also imply that the production function is monotonically increasing and that an increase in marginal cost of research to augment one input will induce factor-saving behavior for the other input.
} 
innovation hypothesis. The same could have occurred in Liu and Shumway's (2009) direct econometric test results with variations in the labor/capital input ratio.

However, it does not help with Kawagoe, Otsuka, and Hayami's (1986) rejection of the induced hypothesis in the land/labor or land/fertilizer input ratios. Total public R\&D funds were not found to be significant in any of the equations where land was included as an input (see the first three columns of Table 3). Unlike de Janvry, Sadoulet, and Fafchamps (1991), we fail to find evidence that total public $R \& D$ expenditures bias technical change toward land-saving technology in U.S. agriculture.

Derived estimates for the R\&D concavity parameter $\theta_{i}$ are also reported in Table 3. Except for the intermediate inputs and capital ratio, all estimates are greater than 1.0, as required for a concave innovation possibility frontier. The estimated concavity parameter is highly sensitive both to input pair and to the information used to estimate price expectations, but none is significantly different from one. The variance of the input quantity ratio explained by the estimated models ranged from 44 to 89 percent of total variance.

\section{Robustness Checks}

We consider several alternative model specifications to examine the robustness of initial model results. We consider variants of our price expectations assumption, the type of estimator used, and the nature of fixed effects.

\section{Adaptive and Naïve Price Expectations}

We use the adaptive expectations hypothesis and the naïve expectations hypothesis as two alternative specifications in our robustness analysis. To create adaptive expectations, we first forecast prices one year ahead at time $t-k$ using geometrically declining distributed lags on five years of realized prices:

$$
\begin{aligned}
E_{t-k}\left(w_{i s(t-k+1)}\right)= & \varphi w_{i s(t-k)}+\varphi(1-\varphi) w_{i s(t-k-1)}+\varphi(1-\varphi)^{2} w_{i s(t-k-2)}+\cdots \\
& +\varphi(1-\varphi)^{4} w_{i s(t-k-4)}
\end{aligned}
$$

where $\varphi$ denotes the weight. The subsequent, 2-, ..., $k$-year ahead forecasts are sequentially updated as

$$
E_{t-h}\left(w_{i s t}\right)=\sum_{p=1}^{h-1} \varphi(1-\varphi)^{p-1} E_{t-h}\left(w_{i s(t-p)}\right)+\sum_{p=h}^{5} \varphi(1-\varphi)^{p-1} w_{i s(t-p))}
$$

for $h=2, \ldots, k$. We select the optimal weight $\varphi$ based on the Akaike Information Criterion. To ensure that the cumulative weights are over 0.9 within the 
assumed R\&D period (i.e., $\sum_{t=1}^{5} \varphi(1-\varphi)^{t-1}>0.9$ ), we only consider $\varphi=0.4$, $0.5,0.6,0.7,0.8$, and 0.9 . When $\varphi=1$, the expectation of future price is the realized lagged price, $E_{t-k}\left(w_{i s t}\right)=w_{i s(t-k)}$. This is the naïve expectation. Forecasts of future prices from these two expectation hypotheses are created using a single price expectation lagged five years and a weighted average of expected prices lagged two to five years.

\section{Estimation Method}

Based on the two-level CES production function, there are three alternative ways the pairs of input ratios could be combined: labor/land and intermediate inputs/capital, capital/land and intermediate inputs/labor, and intermediate inputs/land and capital/labor. Because the error terms between pairs of equations could be correlated, we estimate the three systems of equations using seemingly unrelated regression (SUR) considering rational price expectations lagged five years and a weighted average of expected prices lagged two to five years.

To assess omitted variables bias from ignoring non-neutrality in innovation, we examine the impact of alternative fixed-effects specifications with the fiveyear rational price expectations. We perform pooled regression and one-way (either state dummies or time dummies alone) to determine how empirical support for the IIH would be affected when non-neutrality in innovation supply side is not (or is less rigorously) controlled for.

\section{Robustness Results}

Table 4 documents whether estimated signs and magnitudes of the parameters on current and expected price ratios are consistent with multistage cost minimization conditions and the IIH under each of the alternative specifications. Compared to the test results with the rational expectation hypothesis, somewhat less support for the IIH was found with both the adaptive and naïve expectations. ${ }^{20}$ For capital/labor, intermediate inputs/ labor and intermediate inputs/capital equations, all four of these estimated equations were found to be supportive of the IIH. For labor/land and

20 To see whether the different test results were driven by the different number of observations used in estimation, we also performed the tests using the same number of observations across models with the three expectations hypotheses. To do so, we restricted data included in estimation to be the largest intersection of data used in the original estimation based on each expectation hypothesis. As a result, 1,584 observations were used to estimate the labor/land, capital/land, and intermediate inputs/land equations, and 1,728 observations were used to estimate the capital/labor, intermediate inputs/labor, and intermediate inputs/capital equations with all price expectation specifications. Except for the capital/labor equation, test conclusions were not different from the results using all available data. 
Table 4. Parameter Signs and Magnitudes Consistent with the IIH and Cost Minimization, Alternative Price Expectations, and Estimation Methods ${ }^{a}$

\begin{tabular}{|c|c|c|c|c|c|c|}
\hline Estimation Method & $\begin{array}{l}\text { Labor/ } \\
\text { Land }\end{array}$ & $\begin{array}{l}\text { Capital/ } \\
\text { Land }\end{array}$ & $\begin{array}{l}\text { Intermediate } \\
\text { inputs/Land }\end{array}$ & $\begin{array}{l}\text { Capital/ } \\
\text { Labor }\end{array}$ & $\begin{array}{l}\text { Intermediate } \\
\text { inputs/Labor }\end{array}$ & $\begin{array}{l}\text { Intermediate } \\
\text { inputs/Capital }\end{array}$ \\
\hline \multicolumn{7}{|l|}{$\underline{\text { Price Expectation }}$} \\
\hline Adaptive Expectations, Single Price & Yes & No $\left(\beta_{i 2}\right)$ & Yes & Yes* & Yes* & Yes* \\
\hline Adaptive Expectations, Weighted Price & Yes & No $\left(\beta_{i 2}\right)$ & Yes & Yes* & Yes* & Yes* \\
\hline Naïve Expectations, Single Price & Yes & Yes & Yes & Yes* & Yes* & Yes* \\
\hline Naïve Expectations, Weighted Price & No $\left(\beta_{i 2}\right)$ & No $\left(\beta_{i 1}\right)$ & No $\left(\beta_{i 1}\right)$ & Yes* & Yes* & Yes* \\
\hline \multicolumn{7}{|l|}{ Estimation Method } \\
\hline SUR, Single Price Forecast & Yes* & Yes* & Yes* & Yes & Yes* & Yes \\
\hline SUR, Weighted Price Forecast & No $\left(\beta_{i 2}\right)$ & Yes* & Yes & Yes & Yes* & Yes* \\
\hline Two-way Fixed Effects ${ }^{b}$ & Yes* & Yes* & Yes* & Yes* & Yes & Yes* \\
\hline Pooled Regression ${ }^{b}$ & Yes* & Yes* & Yes* & No $\left(\beta_{i 1}\right)$ & Yes* & Yes* \\
\hline State Fixed Effects ${ }^{b}$ & No $\left(\beta_{i 2}\right)$ & No $\left(\beta_{i 2}\right)$ & No $\left(\beta_{i 2}\right)$ & No $\left(\beta_{i 1}\right)$ & Yes* & Yes* \\
\hline Time Fixed Effects ${ }^{b}$ & Yes* & Yes* & Yes* & Yes* & Yes* & No $\left(\beta_{i 2}\right)$ \\
\hline
\end{tabular}

a "Yes" indicates that the estimate is consistent (in terms of sign) with the IIH and cost minimization conditions, and the asterisk $(*)$ indicates that the estimate is statistically significant at the 10 percent level; "No $\left(\beta_{i 1}\right)$ " and "No $\left(\beta_{i 2}\right)$ ", respectively, indicate that the elasticity of substitution is negatively estimated or that the expected input price ratio positively affects the input quantity ratio.

$\mathrm{b}$ Based on a single five-year rational expectations price forecast. 
intermediate inputs/land, three of the four estimates had expected signs and magnitudes, but none was statistically significant.

The SUR results provided the same support for the IIH as previously (50 percent) when using the weighted average of price expectations and slightly lower support than previously (67 percent vs. 83 percent) when using a single price expectation lagged five years.

While all parameters were consistent with cost minimization and the IIH with two-way fixed effects, inconsistencies were found with each of the alternative fixed-effects specifications. Not accounting for time fixed effects results in four input pairs being inconsistent with the joint hypothesis. Failing to account either for state fixed effects or any fixed effects (i.e., pooled regression) results in one input pair being inconsistent with the joint hypothesis.

Considering only statistically significant estimates, five of the six input pairs were consistent with the joint hypothesis when estimated using two-way fixed effects, time fixed effects, or pooled regression. Only two were consistent when estimated using state fixed effects.

The null hypothesis that fixed effects are zero was soundly rejected at the 1 percent level of significance in all specifications. Thus, unobserved state and time effects are concluded to be important for explaining changes in relative input demands. Two-way fixed-effects estimation provides the greatest support for cost minimization and the IIH. Any omitted variables bias in the alternatives reduces support for this joint hypothesis. ${ }^{21}$

\section{Assessment}

Considering non-neutrality in innovation as an omitted variables issue, a moderate level of support for the IIH and multistage cost minimization was found using 1960-2004 U.S. agricultural state-level data. With input prices assumed to be formulated via rational expectations, $2 / 3$ of the individually estimated equations provided support for the IIH. That dropped to half under adaptive and naïve input price expectations. Considering all 48 two-way fixed-effects equations estimated, 27 (57 percent) provided support for the IIH. Empirical evidence of consistency with the IIH was concentrated in three input pairs: intermediate inputs/labor, intermediate inputs/capital, and capital/labor, with 88 percent, 88 percent, and 75 percent support, respectively. All input ratios that included land provided much less consistency with the IIH, with support ranging from 25 to 38 percent.

The overall level of support for the IIH found here using readily available demand-side price and allocation data is similar to the 59 percent support found by Cowan, Lee, and Shumway (2015) in their recent tests accounting

21 Using longer lags with our relatively short data series also reduced support for the IIH. 
for non-neutrality in innovation supply based on public R\&D expenditures data. In both cases, the greatest support was found for intermediate inputs and least support for land and labor. Ours differed from theirs only in that relative support was reversed for labor and land. Thus, the emerging evidence of support for the IIH in this industry when innovation supply is accounted for is considerably greater than that found in several other studies that treated innovation supply as input neutral (e.g., Olmstead and Rhode 1993, Machado 1995, Liu and Shumway 2006, Liu and Shumway 2009).

Our results are consistent with other literature (e.g., Huntington 2010) that finds that technical change includes both price-induced and exogenous components. Our lower level of support for the IIH in land choices may be attributed to the relative fixity of this input. Land is often documented in the dynamic adjustment literature on the agricultural industry as a quasi-fixed input (e.g., Vasavada and Chambers 1986, Taylor and Kalaitzandonakes 1990). Quasi-fixity implies that high adjustment costs hinder immediate response to shocks such as prices and possibly new technology. In such a case, the adjustment rate toward the optimal input utilization would be sluggish.

\section{Conclusions}

Most tests of the induced innovation hypothesis (IIH) with its important policy implications have implicitly maintained the untenable hypothesis of a neutral innovation function. Relying on demand-side data, they have not accounted for differences in the marginal cost of augmenting different inputs. However, because data for the supply side of innovation are seldom available, this obstacle has appeared insurmountable.

In this paper, we document that, with panel data, a two-way fixed-effects estimation procedure can accommodate a time-varying and non-neutral innovation function in the absence of data on marginal $R \& D$ costs. Considering a two-level CES production function and a homothetic innovation function, we also derive the complete set of multistage optimization conditions that build a parametric connection between expected price ratios and factor augmentation, between factor augmentation and cost-minimizing input allocations, and thus between the expected price ratio and subsequent cost-minimizing input allocations.

Our analytical results show that when the elasticity of substitution between two inputs is less than one plus the magnitude of the innovation concavity parameter (which must be greater than one), a rise in the relative expected price of an input results in its relatively lower use. However, when the elasticity of substitution is greater than this magnitude, the IIH implies relatively greater use of the input that is expected to become more expensive. We document that the relationship between expected input prices and factor augmentation is a non-monotonic function of the elasticity of substitution when the innovation function is accounted for. We also find that the 
relationship between marginal $\mathrm{R} \& \mathrm{D}$ cost and factor-saving behavior is a nonmonotonic function of the elasticity of substitution.

We test whether the IIH holds in U.S. agriculture under multistage cost minimization for the period 1960-2004 using only state-level panel input price and quantity and total output data for the agricultural production sector and total public agricultural R\&D expenditures. Our test procedure imposes only one simplifying assumption on the innovation function-that the trend in the rate of change in marginal R\&D cost is the same across observation units. This two-way fixed-effects formulation permits the costminimizing input ratio effects of unobserved differences in marginal R\&D costs across observation units and over time to be controlled for, which could have otherwise caused omitted variables bias. Because the remaining simplifying assumption is an important limitation, albeit much less severe than employed in previous tests, our approach is admittedly only one important step in addressing non-neutral innovation functions.

We implement our test using a rational expectations specification of future input prices at the time $R \& D$ resource allocation decisions are made. Homotheticity conditions on both innovation-creating and innovationimplementing industries are imposed only as local conditions. We then conduct several robustness checks, including alternative price expectation specifications and alternative estimation methods.

We find empirical evidence of consistency with the IIH and cost-minimizing behavior concentrated in input decisions involving pairs of three inputscapital, intermediate inputs, and labor. Considerably less support is evident for input pairs involving land. The level of support for the IIH is similar to recent tests for the IIH in this industry when innovation supply is accounted for (Cowan, Lee, and Shumway 2015) and considerably greater than that found in several other studies that treated innovation supply as input neutral (e.g., Olmstead and Rhode 1993, Machado 1995, Liu and Shumway 2006, Liu and Shumway 2009). Support is greater when input prices are formulated via the rational expectations hypothesis than when they are based on other common expectations mechanisms. It is also greater when two-way fixedeffects estimation is used.

\section{Supplementary material}

The supplementary material that includes appendices, data and code for this article can be found at https://doi.org/10.1017/age.2020.1

\section{References}

Acemoglu, D. 2002. “Directed Technical Change.” Review of Economic Studies 69: 781-809. 2007. "Equilibrium Bias of Technology" Econometrica 75(5): 1371-1409.

2015. "Localized and Biased Technologies: Atkinson and Stiglitz's New View, Induced Innovations, and Directed Technological Change." Economic Journal 125(583): 443-463. 
Ahmad, S. 1966. "On the Theory of Induced Invention." Economic Journal 76: 344-357.

Armanville, I., and P. Funk. 2003. "Induced Innovation: An Empirical Test." Applied Economics 35: 1627-1647.

Atkinson, A.B., and J.E. Stiglitz. 1969. “A New View of Technical Change." Economic Journal 79(315): 573-578.

Ball, V.E., F.M. Gollop, A. Kelly-Hawke, and G.P. Swinand. 1999. "Patterns of State Productivity Growth in the U.S. Farm Sector: Linking State and Aggregate Models." American Journal of Agricultural Economics 81: 164-179.

Ball, V.E., C. Hallahan, and R. Nehring. 2004. "Convergence of Productivity: An Analysis of the Catch-Up Hypothesis within a Panel of States." American Journal of Agricultural Economics 86: 1315-1321.

Bertrand, M., E. Duflo, and S. Mullainathan. 2004. "How Much Should We Trust Differences-inDifferences Estimates?" Quarterly Journal of Economics 119(1): 249-275.

Binswanger, H.P. 1974a. "A Microeconomic Approach to Induced Innovation." Economic Journal 84(336): 940-958.

1974b. "The Measurement of Technical Change Biases with Many Factors of Production." The American Economic Review 64(6): 964-976.

Bray, M. 1981. "Futures Trading, Rational Expectations, and the Efficient Markets Hypothesis." Econometrica 49(3): 575-596.

Brown, D.J. 2014. "Approximate Solutions of the Walrasian Equilibrium Inequalities with Bounded Marginal Utilities of Income." Cowles Foundation Discussion Paper No. 1955, Yale University.

Chavas, J.P., and T.L. Cox. 1992. "A Nonparametric Analysis of the Influence of Research on Agricultural Productivity." American Journal of Agricultural Economics 73(3): 583-591.

Cowan, B.W., D. Lee, and C.R. Shumway. 2015. "The Induced Innovation Hypothesis and U.S. Public Agricultural Research." American Journal of Agricultural Economics 97(3): 727-42.

Crabb, J.M., and D.K.N. Johnson. 2010. "Fueling Innovation: The Impact of Oil Prices and CAFÉ Standards on Energy-Efficient Automotive Technology." Energy Journal 31: 199-216.

Deininger, K.W. 1995. Technical Change, Human Capital, and Spillovers in United States Agriculture, 1949-1985. London: Routledge.

de Janvry, A., E. Sadoulet, and M. Fafchamps. 1991. "Agrarian Structure, Technological Innovations, and the State." Chapter 18 in P.K. Bardhan, ed. The Economic Theory of Agrarian Institutions. Cambridge: Oxford University Press.

Esposti, R., and P. Pierani. 2006. "Price-Induced Technical Progress in Italian Agriculture." Review of Agricultural and Environmental Studies 89(4): 5-28.

Fulginiti, L.E. 1994. "Price-Conditional Technology." Journal of Agricultural and Resource Economics 19(1): 161-72.

Funk, P. 2002. "Induced Innovation Revisited.” Economica 69: 155-171.

Gardner, B.L. 1976. "Futures Prices in Supply Analysis." American Journal of Agricultural Economics 58(1): 81-84.

Gertchev, N. 2007. "A Critique of Adaptive and Rational Expectations." Quarterly Journal of Austrian Economics 10: 313-329.

Hayami, Y., and V.W. Ruttan. 1970. "Factor Prices and Technical Change in Agricultural Development: The United States and Japan, 1880-1960." The Journal of Political Economy 78: 1115-1141.

Hicks, J.R. 1932. The Theory of Wages. London: Macmillan.

Hommes, C.H. 1998. "On the Consistency of Backward-looking Expectations: The Case of the Cobweb." Journal of Economic Behavior \& Organization 33: 333-362.

Huffman, W.E. 2012. "Public Agricultural Research Expenditure and Stock Data by State, 1927-2009." Iowa State University, Personal communication.

Huffman, W.E. 2015. "Measuring Public Agricultural Research Capital and Its Impact on State Agricultural Productivity in the United States.” In L. Singh, K.J. Joseph, and D.K. Johnson, 
eds. Technology, Innovations and Economic Development: Essays in Memory of Robert E. Evenson. New Delhi: Sage.

Huffman, W.E., and R. Evenson. 1989. "Supply and Demand Functions for Multiproduct U.S. Cash Grain Farms: Biases Caused by Research and Other Policies. American Journal of Agricultural Economics 71(3): 761-773.

- 2006. "Do Formula or Competitive Grant Funds Have Greater Impacts on State Agricultural Productivity?" American Journal of Agricultural Economics 88(4): 783-798.

Huntington, H.G. 2010. "Oil Demand and Technical Progress." Applied Economics Letters 17: 1747-1751.

Im, K.S., M.H. Pesaran, and Y. Shin. 2003. "Testing for Unit Roots in Heterogeneous Panels." Journal of Economics 115: 53-74

Johnstone, N., I. Hascic, J. Poirier, M. Hemar, and C. Michel. 2012. "Environmental Policy Stringency and Technological Innovation: Evidence from Survey Data and Patent Counts." Applied Economics 44: 2157-2170.

Kamien, M.I., and N.L. Schwartz. 1968. “Optimal 'Induced' Technical Change." Econometrica 36: 1-17.

Kawagoe, T., K. Otsuka, and Y. Hayami. 1986. "Induced Bias of Technical Change in Agriculture: The United States and Japan, 1880-1980." Journal of Political Economy 94 (3): 523-544.

Kennedy, C. 1964. "Induced Bias in Innovation and the Theory of Distribution." Economic Journal 74(295): 541-547.

Lim, H., and C.R. Shumway. 1992. "Profit Maximization, Returns to Scale, and Measurement Error." Review of Economics and Statistics 74(August): 430-438.

Liu, Q., and C.R. Shumway. 2006. "Geographic Aggregation and Induced Innovation in American Agriculture." Applied Economics 38: 671-682.

Liu, Y., and C.R. Shumway. 2009. "Induced Innovation in U.S. Agriculture: Time-series, Econometric, and Nonparametric Tests." American Journal of Agricultural Economics 91(1): 224-236.

Machado, F.S. 1995. "Testing the Induced Innovation Hypothesis Using Cointegration Analysis." Journal of Agricultural Economics 46(3): 349-360.

McIntosh, C.S., and C.R. Shumway. 1994. "Evaluating Alternative Price Expectation Models for Multiproduct Supply Analysis. Agricultural Economics 10(1): 1-11.

Olmstead, A.L., and P. Rhode. 1993. "Induced Innovation in American Agriculture: A Reconsideration." Journal of Political Economy 101: 100-118.

Pedroni, P. 2004. "Panel Cointegration: Asymptotic and Finite Sample Properties of Pooled Time Series Tests with an Application to the PPP Hypothesis." Econometric Theory 20 (3): 597-625.

Piesse, J., D. Schimmelpfennig, and C. Thirtle. 2011. "An Error Correction Model of Induced Innovation in UK Agriculture." Applied Economics 43: 4081-4094.

Popp, D. 2002. "Induced Innovation and Energy Prices." The American Economic Review 92: 160-180.

Samuelson, P.A. 1965. "A Theory of Induced Innovation along Kennedy-Weisäcker Lines." Review of Economics and Statistics 47(4): 343-356.

Shonkwiler, J.S., and G.S. Maddala. 1985. "Modeling Expectations of Bounded Prices: An Application to the market for Corn." Review of Economics and Statistics 67: 697-702.

Taylor, T.G., and N. Kalaitzandonakes. 1990. "A Test of Asset Fixity in South-Eastern U.S. Agriculture." Southern Journal of Agricultural Economics 22: 105-111.

Thirtle, C.G., D.E. Schimmelpfennig, and R.E. Townsend. 2002. "Induced Innovation in United States Agriculture, 1880-1990: Time Series Tests and an Error Correction Model." American Journal of Agricultural Economics 84: 598-614.

USDA Economic Research Service. 2015. "Agricultural Productivity in the U.S." http://ers. usda.gov/data-products/agricultural-productivity-in-the-us.aspx\#28247, Table 23. 
2017. "Agricultural Productivity in the U.S." http://ers.usda.gov/data-products/ agricultural-productivity-in-the-us.aspx\#28247, Table 1 a.

Vasavada, U., and Chambers, R.G. 1986. "Investment in U.S. Agriculture." American Journal of Agricultural Economics 68(4): 950-960.

Wang, S.L., P.W. Heisey, W.E. Huffman, and K.O. Fuglie. 2013. "Public R\&D, Private R\&D, and U.S. Agricultural Productivity Growth: Dynamic and Long-Run Relationships." American Journal of Agricultural Economics 95: 1287-1293.

Wooldridge, J.M. 2002. Economic Analysis of Cross Section and Panel Data. Cambridge, MA: MIT Press. 